\title{
Characterization Study of EPDM Rubber Vulcanized by Gamma Radiation in The Presence of Epoxidized Soybean Oil
}

\section{H. Radi and I. M. Mousaa}

Radiation Chemistry Dept., National Centre for Radiation Research and Technology (NCRRT), P.O. Box; 29, Naser city, Egypt.

\footnotetext{
COMPOSITES based on ethylene-propylene-diene rubber (EPDM) were prepared. EPDM loaded with $40 \mathrm{phr}$ fumed silica in the presence of different concentrations of epoxidized soybean oil ranging between 4 and $8 \mathrm{phr}$. The composites were subjected to various gamma irradiation doses up to $200 \mathrm{kGy}$.

The physical, mechanical and thermal properties of rubber composition as a function of irradiation dose were investigated. Gamma irradiation led to a significant improvement in the properties of the all compositions. Besides, an improvement in the mechanical properties was attained with the addition of 4 phr of epoxidized soybean oil.

Keywords: EPDM, rubber, epoxidized soybean oil, $\gamma$-rays.
}

EPDM rubber has a stable and saturated polymer backbone structure. Due to this, EPDM is found to have an excellent resistance to heat, oxidation, ozone and weather ageing. Also EPDM, because of their excellent electrical insulation properties, are widely used in wire and cable coatings. The increasing demand for EPDM in electrical applications is also due to its excellent resistance to degradation and ease of accepting large amounts of fillers (Chazeau et al., 2010).

High-energy radiation is a well-known technique for modification of polymers. Radiochemical studies on cross linking or degradation of polymers are important for designing new materials (Samarzija-Jovanovic et al., 2014). Radiation can produce crosslink densities like those obtained by sulphur curing, but the net effects, while similar, are not identical. The type of crosslink formed in this method $(-\mathrm{C}-\mathrm{C}-)$ give rise to better mechanical properties at higher temperature (Markovic et al., 2013). This might be reflected in better high temperature performance as higher hot tear strength. Also, it can lead to greater abrasion resistance (Jovanovic et al., 2013) and superior ozone resistance (Abou Zeid et al., 2008). 
Electron beam and gamma irradiations are employed to cure rubber. These methods like peroxide cross linking lead to $\mathrm{C}-\mathrm{C}$ bonds. As opposed to peroxide or sulphur curing, no heating of the material is necessary. The efficiency of the cross linking mode depends not only on the chemical composition of the polymer, but also on the presence of additives, such as antioxidants, which are generally incorporated to reduce excessive degradation while curing at high temperature and during subsequent aging. The mechanical properties of the networks are drastically depending on the curing mode. One reason for that is the nature of the chemical bonds formed between the chains and the functionality of the cross links. The other is attributed to the differences of heterogeneity i.e., distribution of cross links and defects in the networks (Gehman, 1969 and Mark, 1988). Grobler et al. Grobler et al. (1994) found that, for polyisoprene the heterogeneity of the network decreased in the following order: conventional sulphur more than efficient sulphur more than peroxide which is more than $\gamma$-rays irradiation. EPDM rubber has been used in a hard radiation environment due to its high resistance to environmental effects compared to other types of rubbers (IAEA, 2000 and Masayuki, 2007). The use of EPDM rubber in high radiation environment makes it one of the most studied polymers in the area of polymer degradation. The structure of the EPDM contains fully saturated bonds in the main chain with lack of quaternary carbon atom. Double bonds in EPDM are pendant to the main chain which comes from dienes such as ethylidenenorborneneand1, 4-hexadiene (Dyson, 1990). Therefore, these properties make EPDM rubber as cross linkable polymers under ionizing radiation. Radiation can induce additional cross linking and/or scission of the polymeric chain. The evolution of a commercial product will depend on the fillers and additives nature and content, and dose rate,

In this study, change of EPDM's mechanical, physical, and thermal properties as a function of gamma irradiation was investigated. Moreover, the effects of irradiation dose, concentration of epoxidized soybean oil, were studied to investigate the change in the properties of EPDM via gamma irradiation.

\section{Materials and experimental techniques}

\section{Materials}

EPDM rubber of Vistalon 5600 type is characterized by an ethylene content of $60 \mathrm{wt} \%$, a specific gravity of $0.86 \mathrm{~g} / \mathrm{cm} 3$ and Ash\% wt. 0.3, supplied

Egypt. J. Rad. Sci. Applic., Vol. 28, No. 1-2 (2015) 
by Exxon chemical company (Belgium).The composite used for this study also contain additives such as zinc oxide as an accelerator and Stearic acid as an activator. Pure epoxidized soybean oil having oxirane oxygen content $6 \%$ was delivered from Paint and Chemical Industry, Egypt and the fumed silica used supplied by weaker silicones company, Germany.

\section{Experimental techniques}

\section{Preparation of formulated samples}

All ingredients of the selected formulation were weighed; mixing was carried out on a laboratory rubber mill type 150 . The additives were mixed with the rubber, bonded on the slow rolls, and temperature of the surface of the rolls was controlled during mixing. Sheets of $\sim 1 \mathrm{~mm}$ in thickness were then obtained by compression moulding between Holland cloth in clear and polished moulds of an electrically heated hydraulic press.

\section{Irradiation procedure}

Radiation of samples was carried out at NCRRT, Nasr city, Egypt. A cobalt- 60 source of $\gamma$-rays of the type of gamma chamber-4000A manufactured by Bhabba Atomic Research Centre, Bombay, India was used for irradiation giving a dose rate of about $1 \mathrm{kGy} / \mathrm{h}$.

\section{Measurements}

Dumbbll-shaped specimens were cut from the sheets using a steel die of standard width of $4 \mathrm{~mm}$ and length of $15 \mathrm{~mm}$. A gauge graduated to hundredth of $\mathrm{mm}$ was used to determine the thickness of the test sample. The measurements of tensile strength (TS) and percentage of elongation at break point (E \%) was carried out using a mechanical testing machine of hung-Ta instruments LTD Company, Taiwan. The soluble fraction was obtained by extracting the samples $\left(\mathrm{W}_{0}\right)$ in acetone using a Soxhlet system for $24 \mathrm{~h}$. The extracted samples were dried in a vacuum oven at $60^{\circ} \mathrm{C}$ to a constant wt $(\mathrm{W})$. The soluble fraction is equal to: $\left(\mathrm{W}_{0}-\mathrm{W} / \mathrm{W}_{0}\right)$. TGA was carried out with samples of $(3-5 \mathrm{mg})$ encapsulated in aluminium pans and heated from room temperature up to $700^{\circ} \mathrm{C}$; using a TG-50 instrument from Shimadzu, Japan with a heating rate $10^{\circ} \mathrm{C} / \mathrm{min}$. Measurements were carried out under insert atmosphere of nitrogen gas. 


\section{Result and discussion}

\section{Mechanical properties}

EPDM rubber is amorphous terpolymer and not easily crystallisable, it is necessary to introduce reinforcing filler, namely fumed silica to produce a vulcanized rubber with reasonable mechanical properties (Motawie et al. 2010), so the samples were prepared from raw elastomer compounded with reinforced 40phr fumed silica as a filler and a different concentrations of epoxidized soybean oil, namely 4, 6, and 8phr (the blank sample is EPDM with 40phr fumed silica). Irradiation of EPDM resulted in formation of macro radicals, which may be represented by the radiation mechanism of EPDM as shown in Scheme 1. (Ahmadi et al., 2009).

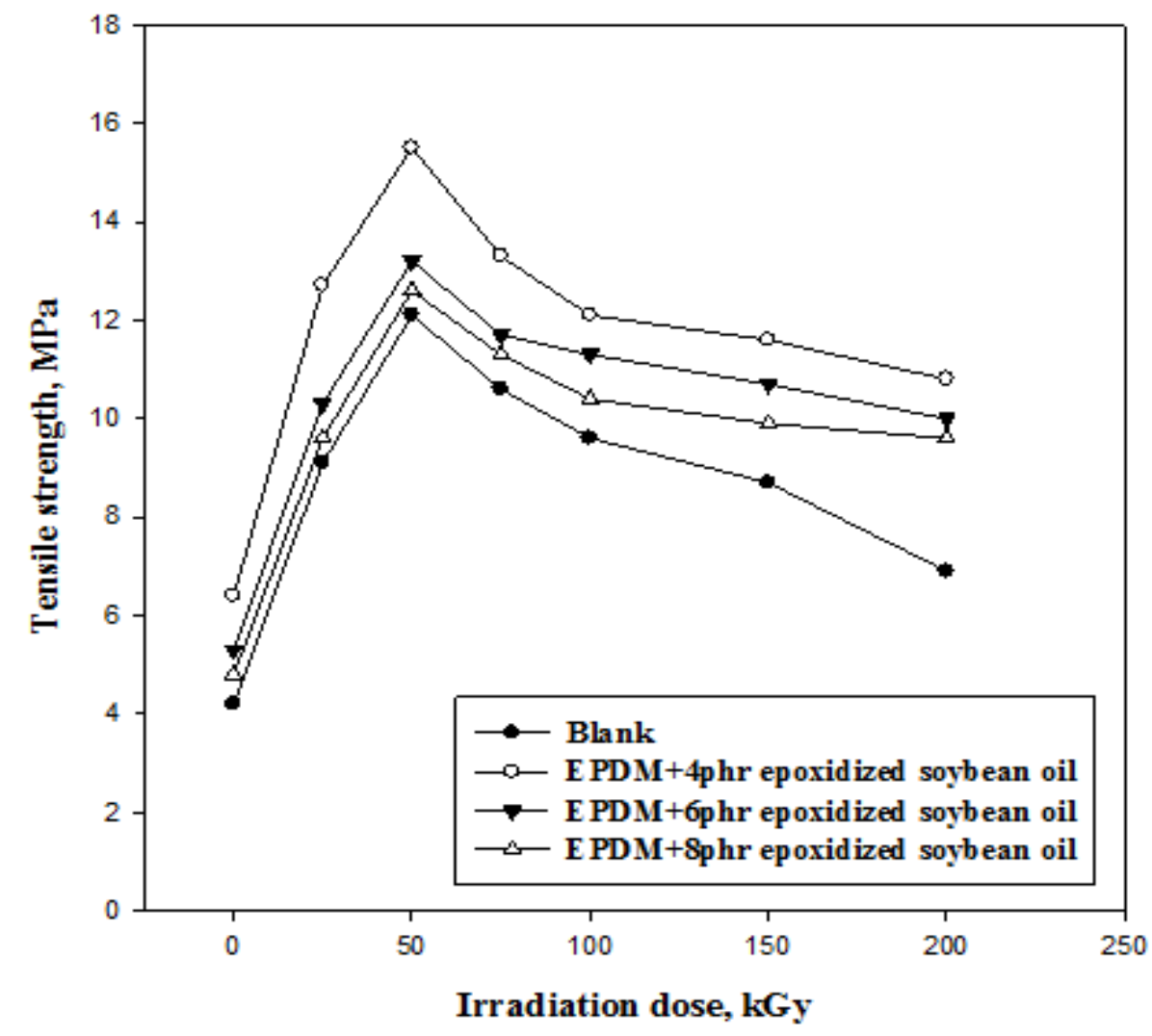

Fig. 1. Tensile strength against irradiation dose of EPDM rubber loaded with $40 \mathrm{phr}$ fumed silica with different concentrations of epoxidized soybean oil.

Egypt. J. Rad. Sci. Applic., Vol. 28, No. 1-2 (2015) 
One of the clearest effects of irradiation of elastomer due to their crosslinking and degradation is the change in tensile strength TS. Fig. 1. shows the variation of TS as a function of irradiation dose of EPDM rubber loaded with $40 \mathrm{phr}$ from fumed silica and enhanced with different concentrations of epoxidized soybean oil, namely, 4, 6, and 8phr. From Fig. 1 it can be seen that the values of TS for all compositions increase with increasing irradiation dose reaching its maximum values at about 50kGy and after that, the values of TS decrease slowly on increasing the irradiation dose up to $200 \mathrm{kGy}$.

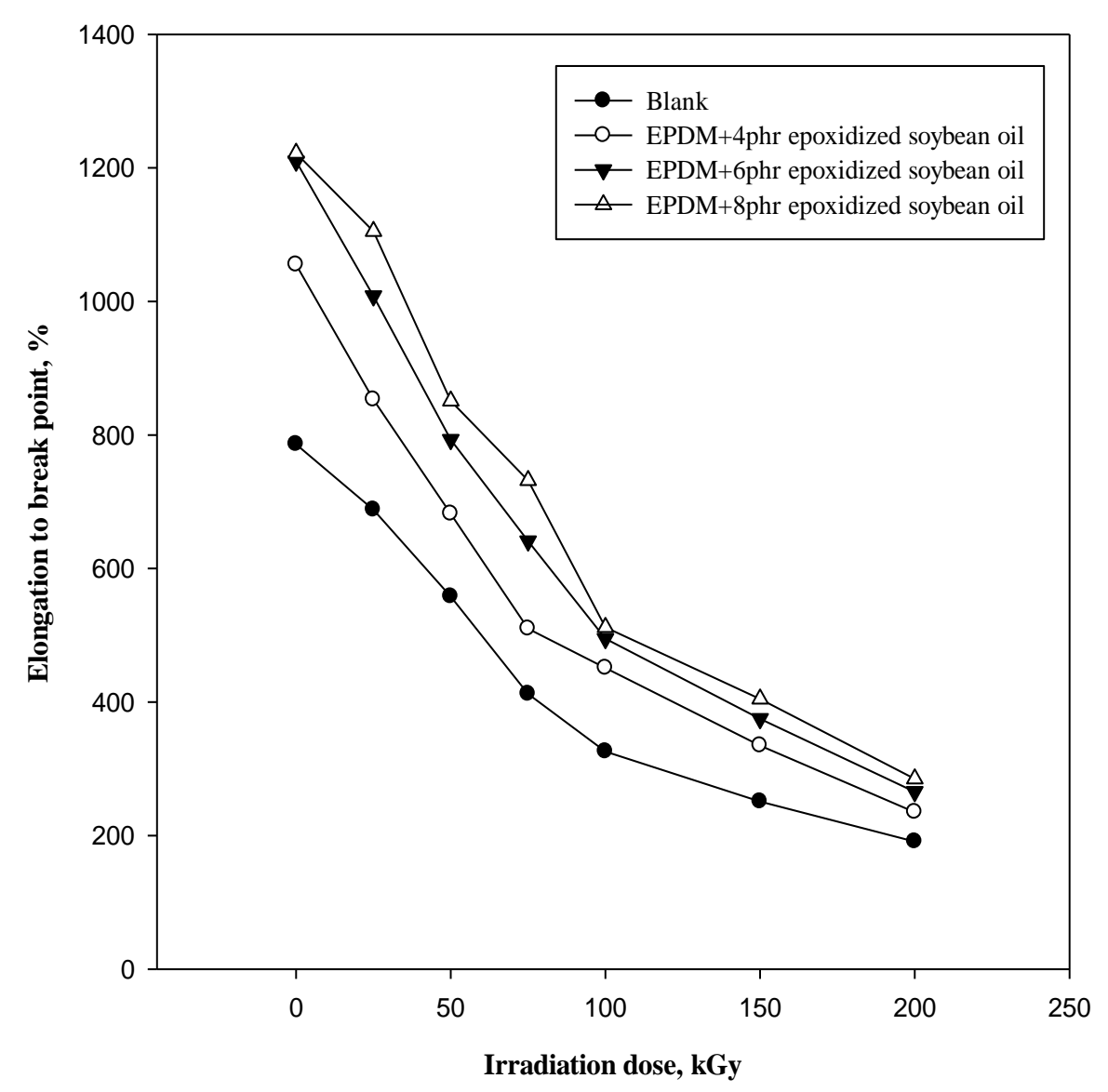

Fig. 2. Elongation at break point against Irradiation dose of EPDM rubber loaded with 40phr fumed silica with different concentrations of epoxidized soybean oil.

Egypt. J. Rad. Sci. Applic., Vol. 28, No. 1-2 (2015) 

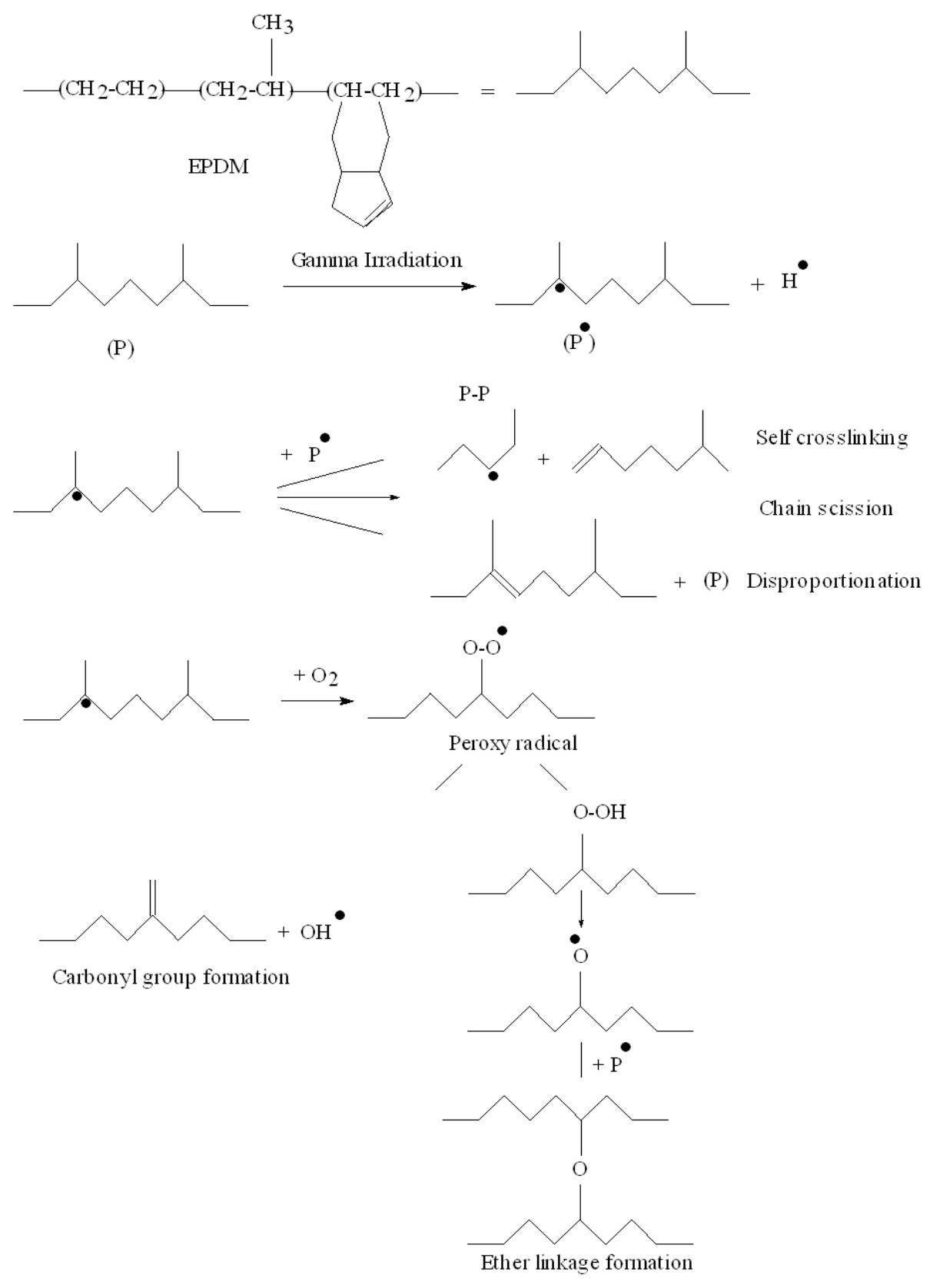

Scheme 1. Radiation mechanism of EPDM rubber.

Egypt. J. Rad. Sci. Applic., Vol. 28, No. 1-2 (2015) 
Also from Fig. 1. it can be seen that the addition of the epoxidized soybean oil leads to relatively increase of TS values (especially at $4 \mathrm{phr}$ from the epoxidized soybean oil). This increase may be due to the presence of epoxy groups in the chain of the epoxidized soybean oil make it very sensitive to irradiation, which in turn leads to formation of free radicals (see scheme 2) (Abdel Aziz et al., 2010). Also epoxy groups may increase the compatibility between the fumed silica and rubber by modifying the surface of silica which improve its interaction with hydrocarbon rubber i.e., it may act as a centre of linkage between fumed silica and rubber.<smiles>CC1OC1C</smiles>

Epoxidized oil

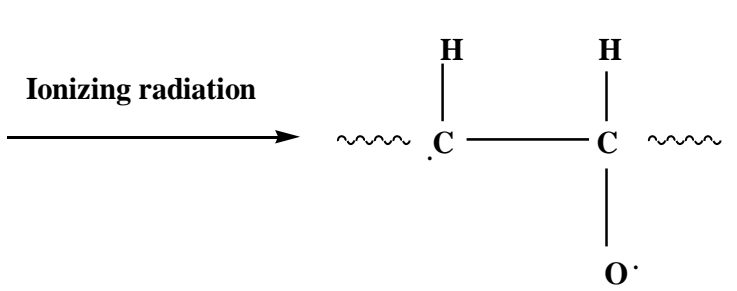

Radical

Scheme 2. Effect of radiation on epoxidized oil.

Another factor, which affects the behaviour of TS as irradiation dose increased, is the degradation process, where the breakage of carbon-carbon bond of the main rubber chain may take place with higher rate than the crosslinking process. Accordingly, decrease in the TS values would be expected. In other word, radiation causes two competing reactions for rubber compounds namely, crosslink formation and scission of chains.

Fig. 2. illustrates the variation of elongation at break point $(\mathrm{E} \%)$ as a function of irradiation dose of the above mentioned samples. From Fig. 2, it can be seen that, the values of $\mathrm{E} \%$ for all compositions decreases with different rates with increasing the irradiation dose depending on the susceptibility of each formulation to the radiation dose to form free radicals. Therefore, cross-linking density increased and hence, the hindrance of the mobility of the molecular chains increased which resulted in decrease in $\mathrm{E} \%$.

Also from Fig. 2. we can observe that, the addition of the epoxidized soybean oil increase the $\mathrm{E} \%$ of the rubber with increasing the concentration of the epoxidized soybean oil, this is due to the fact that; epoxidized soybean oil may act as very good plasticizer.

Egypt. J. Rad. Sci. Applic., Vol. 28, No. 1-2 (2015) 


\section{Soluble fraction (SF)}

The polymeric system breaks into two phases by radiation. Some of the initial molecules are linked together to form an infinite network, which is insoluble and referred to as the gel fraction.

Another fraction of molecules remains soluble. These molecules are separate from the network although they may be highly branched and constitute the soluble fraction which can be extracted from the bulk polymer by the use of a proper solvent (Chapiro, 1962). In addition, the degree of solubility of the cross-linked polymers depends on the cross-linking density and hence, the irradiation dose, and the polymer structure.

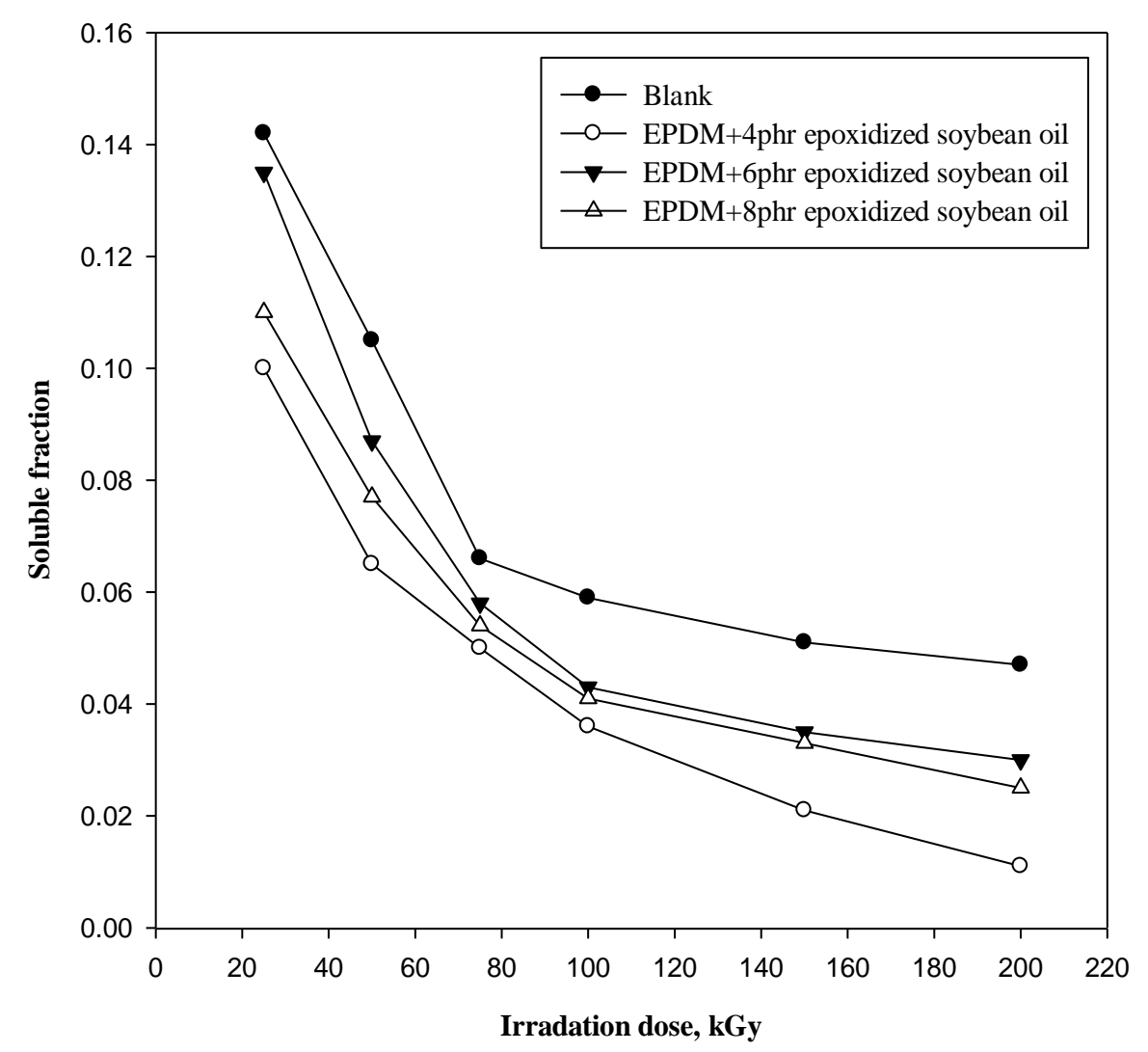

Fig. 3. Soluble fraction against Irradiation dose of EPDM rubber loaded with 40phr fumed silica with different concentrations of epoxidized soybean oil

Egypt. J. Rad. Sci. Applic., Vol. 28, No. 1-2 (2015) 
Fig. 3. shows the variation of SF (in acetone) as a function of irradiation dose for the above mentioned samples. From Fig. 3. It can be seen that, SF of EPDM decreases sharply with increasing the irradiation dose from 25 to $75 \mathrm{kGy}$ then decrease with slow rate up to $100 \mathrm{kGy}$ after which the value of SF have almost levelled off up to highest irradiation dose used in this investigation, namely, 200kGy. Moreover it can be seen that the addition of epoxidized soybean oil leads to increase in the cross-link density i.e., decrease in the SF, this decrease is increased with increasing the concentration of the epoxidized soybean oil.

\section{Thermo gravimetric analysis (TGA)}

Polymeric material: whether as it is or as a composite are used frequently in several applications at elevated temperature. Hence, gaining information about their thermal stability under such kind of application is beneficial and necessary under such circumstances (Mucha, 1976). Moreover, the incorporated additives probably have some effects on the thermal stability of polymer as well as their composites. Dynamic thermogravimetry (with linear temperature increase) is widely used as a tool to study the degradation of different polymeric material, elucidate the order of reaction and also to estimate other kinetic parameters such as the activation energy, the frequency factor, and the rate of decomposition (Dickens, 1980). The thermo-gravimetric data presented in Fig. 4. Show the variation of residual wt fraction percentage (RWF \%) as a measure of the wt loss of EPDM rubber incorporated with 40phr fumed silica in the presence of 4, 6, and 8phr epoxidized soybean oil as a function of heating temperature and irradiated with $75 \mathrm{kGy}$. The temperatures at which different weight loss, namely, 10, 20, and 40\% occurred for these samples are shown in Table 1. From Fig. 4. it can be seen that the thermo grams obtained for samples are characterized by being single stepped indicating one distinct pyrolysis process has been taken place on heating the samples. On rising the temperature in the range $\sim\left(250-480{ }^{\circ} \mathrm{C}\right)$, the RWF\% values for the thermo grams show a sudden drop and then decreasing slowly up to temperature of $700{ }^{\circ} \mathrm{C}$. The sudden drop occurring in RWF\% may be attributed to the decomposition of the main constituent of the composite, namely the rubber matrix. Compared with the blank sample (EPDM with 40phr fumed silica), it may be observed that it has shifted to a higher temperature range with the addition of 8phr epoxidized soybean oil. Moreover this index may show whether the decomposition occur in a single step or several consecutive steps which can be determined on the basis of the whole shape of the TGA curve.

Egypt. J. Rad. Sci. Applic., Vol. 28, No. 1-2 (2015) 


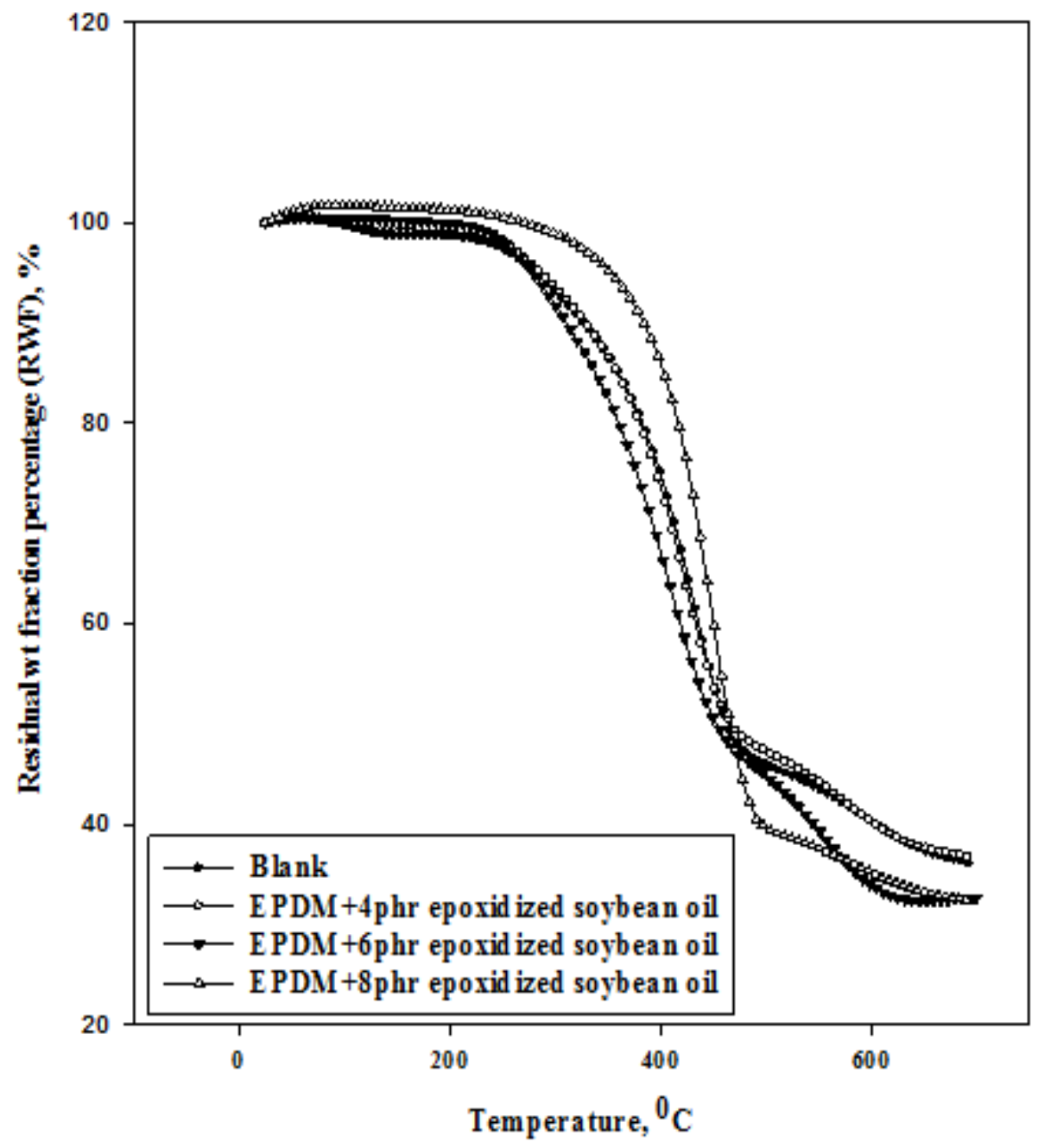

Fig. 4. Residual wt fraction (RWF) against temperature of EPDM rubber irradiated with $75 \mathrm{kGy}$ and loaded with $40 \mathrm{phr}$ fumed silica with different concentrations of epoxidized soybean oil.

Fig. 5. shows the variation of rate of decomposition (dw/dt) as a function of heating temperature for the above mentioned samples and irradiated with $75 \mathrm{kGy}$. From this figure, it can be seen that, the thermo grams obtained for the samples show one maxima at about $430,425,455$, and $450{ }^{\circ} \mathrm{C}$ respectively. Moreover, the addition of epoxidized soybean oil leads to increase of temperature at which the degradation occurs, i.e., the samples becomes more

Egypt. J. Rad. Sci. Applic., Vol. 28, No. 1-2 (2015) 
thermally stable as compared to that enhanced with blank especially at concentration of 6 and $8 \mathrm{phr}$ from the epoxidized oil. In general, the higher thermal stability of the composition containing fumed silica, epoxidized soybean oil, may be due to the oxidation degradation processes and the formation of carbonyl groups with higher dissociation energy than $\mathrm{CH}$ group.

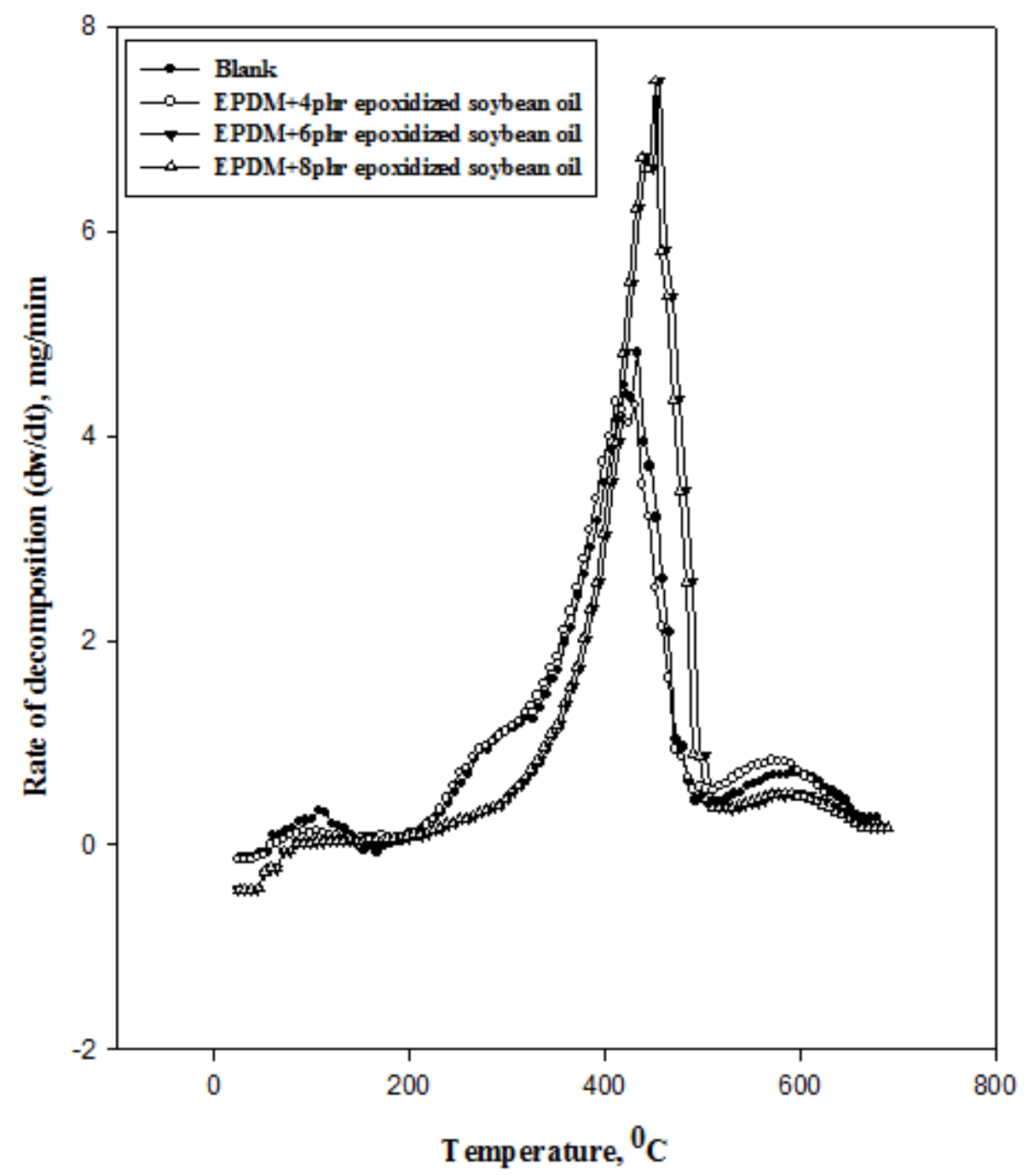

Fig. 5. Rate of decomposition against temperature of EPDM rubber irradiated with $75 \mathrm{kGy}$ and loaded with $40 \mathrm{phr}$ fumed silica with different concentrations of epoxidized soybean oil.

Egypt. J. Rad. Sci. Applic., Vol. 28, No. 1-2 (2015) 
TABLE 1. Temperatures at different weight loss of EPDM rubber loaded with 40phr fumed silica and enhanced with 4, 6, and 8phr epoxidized soybean oil and irradiated to $75 \mathrm{kGy}$.

\begin{tabular}{|c|c|c|c|c|}
\hline \multirow{2}{*}{ Sample type } & \multicolumn{3}{|c|}{$\begin{array}{c}\text { Decomposition temperature } \\
\left.\text { different wt loss } \mathbf{( ~}^{\mathbf{0}} \mathbf{C}\right)\end{array}$} & \multirow{2}{*}{$\mathbf{T}_{\max }$} \\
\cline { 2 - 5 } & $\mathbf{1 0 \%}$ & $\mathbf{2 0 \%}$ & $\mathbf{4 0 \%}$ & \\
\hline blank & 330 & 385 & 435 & 430 \\
\hline EPDM+ 4phr epoxidized oil & 325 & 380 & 430 & 425 \\
\hline EPDM+ 6phr epoxidized oil & 310 & 360 & 420 & 455 \\
\hline EPDM+ 8phr epoxidized oil & 380 & 415 & 448 & 450 \\
\hline
\end{tabular}

\section{Conclusion}

This work was undertaken to study the effects of irradiation of fumed silica-loaded EPDM rubber with different concentrations of epoxidized soybean oil. The following conclusions may be made: First, irradiation of all the compositions improved to a great extent the physical and mechanical properties. In this regard, the tensile strength increased with dose and with the addition of epoxidized soybean oil (especially at 4phr), and elongation at break of the vulcanized rubber is reduced with dose. Second, the results of soluble fraction, showed a good agreement with tensile strength results. Third, the thermal stability of the rubber improved with the addition of epoxidized soybean oil (especially at 6 and $8 \mathrm{phr}$ from the epoxidized soybean oil).

\section{References}

Abel Aziz, M. M., Radi, H. and Rabie, A. M. (2010) Radiation cross- linking of Fumed silica loaded EPDM rubber in the presence of epoxidized linseed oil. J. Rad. Sci. Applic., 23, 131.

Abou Zeid, M. M., Rabie, S. T., Nada, A. A., Khalil, A. M. and Hilal, R. H. (2008) Effect of gamma irradiation on ethylene propylene diene terpolymer rubber composites. Nucl. Instrum. Methods Phys. Res. B., 266, 111.

Ahmadi, S. J., Yu-Dong, H., Nanqi, R., Mohaddespour, A. and Seyed, Y. A. (2009) The comparison of EPDM/clay nanocomposites and conventional composites in exposure of gamma irradiation. J. Composites Sci. Tech., 69, 997.

Chapiro, A. (1962) Radiation Chemistry of Polymeric Systems, John Wily and sons, New York, p. 354.

Chazeau, E. L., Vigier, G., Fournier, J. and Royaud, I. S. (2010) Influence of fillers on mechanical properties of ATH filled EPDM during ageing by gamma irradiation. J. Polym. Degrad. Stab., 95, 1029.

Dickens, B. (1980) Thermal degradation and oxidation of polystyrene studied by factorjump thermogravimetry. J. Polym. Degrad. Stab., 2, 249.

Egypt. J. Rad. Sci. Applic., Vol. 28, No. 1-2 (2015) 
Dyson, R. W. (1990) Engineering Polymers. Blackie \& Son Ltd, New York, p. 85.

Gehman, S. D. (1969) Network chain distribution and strength of vulcanizates. $J$. Rubber Chem. Technol., 42, 659.

Grobler J. H. A. and McGill, W. (1994) Effect of network heterogeneity on tensile and tear strengths of radiation, peroxide, efficient and conventional cured polyisoprene. J. Polym. Sci. B. Polym. Phys., 32, 287.

IAEA (2000) Assessment and Management of Ageing of Major Nuclear Power Plant Components. International Atomic Energy Agency. Technical Report Series, No., 1188, Vienna.

Jovanovic V., Samarzija-Jovanovic, S., Dekic, B., Konstaninovic S. and Markovic, G. (2013) Effect of $\gamma$-irradiation on the thermo-oxidative behavior of nanosilica based urea-formaldehyde hybrid composite with 4-chloro-3-nitro-2Hchromen-2-one. J. Composites Part B, 45, 864.

Mark, H. F. (1988) Elastomers-Past, Present, and Future. J. Rubber Chem. Technol., 61, 73 .

Markovic, G., Veljkovic, O., Jovanovic, V., Samarzija-Jovanovic, S., MarinovicCincovic, M. and Budinski-Simendic (2013) Composites based on waste rubber powder and rubber blends: BR/CSM. J. Composites: Part B, 45, 178.

Masayuki, I. (2007) Degradation of elastomer by heat and/or radiation. Nucl. Instrum. Methods B, 265, 227.

Motawei, A. M., Abdel-Aziz, M. M., Rabie, A. M. and Mazrous, M. M. (2010) Compatibility study of polypropylene and acrylonitrile butadiene rubber blends. J. of App. Sci., 118, 2056.

Mucha, T. (1976) Thermogravimetric studies of polymethylene and polyethylene. $J$. Poly. Sci. 57, 25.

Samarzija-Jovanovic S., Jovanovic, V., Cincovic, M. M., Simendic, J. B. and Markovic, G. (2014) Comparative study of radiation effect on rubbercarbon black compounds. J. Composites: Part B, 62, 183.

(Received: 14/12/2014;

accepted: 23/02/2015)

Egypt. J. Rad. Sci. Applic., Vol. 28, No. 1-2 (2015) 


$$
\begin{aligned}
& \text { دراسة خواص مطاط الايثيلين بروبلين دايين مونيمر المفلكن } \\
& \text { بالاشعاع فى وجود ايبوكسى زيت فول فول الصوين برولين }
\end{aligned}
$$

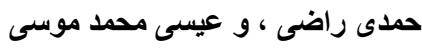

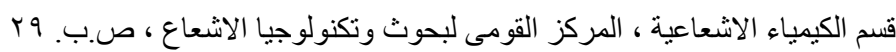

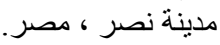

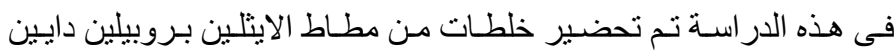

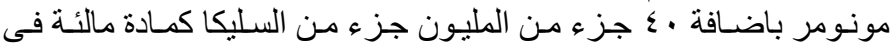

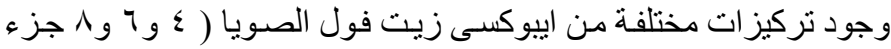

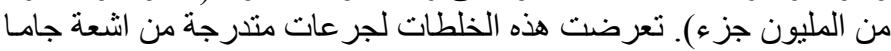

$$
\text { (حتى . . . ب كيلوجر ایى). }
$$

تمت دراسة الخو اص المختلفة لهذه الخلطات.وقد تبين من الدراسة مايلى:

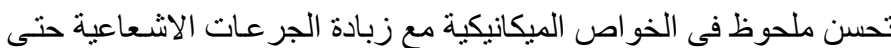
• 0 كيلو جر اى ثم يحدث تدهور فى الخواص بزيادة الجرعة الاشعاعية.

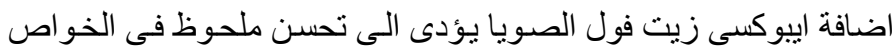

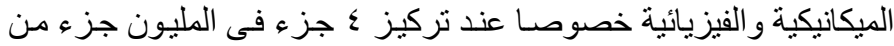

$$
\text { الزيت. }
$$

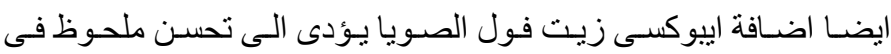

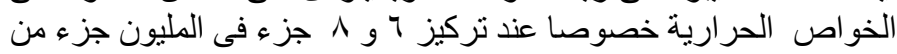

Egypt. J. Rad. Sci. Applic., Vol. 28, No. 1-2 (2015) 